\title{
MODALIDADES DE GESTÃO DO SISTEMA NACIONAL DE UNIDADES DE CONSERVAÇÃO: ESTUDO DE CASO NOS FAXINAIS DO MUNICÍPIO DE MANDIRITUBA, PR
}

\author{
Ana Paula Donicht Fernandes ${ }^{1}$; Vitor Afonso Hoelfich ${ }^{2}$; Anadalvo Juazeiro dos Santos ${ }^{2}$; Evaldo Munoz Braz ${ }^{3}$; \\ Mara Freire Rodrigues de Souza ${ }^{4}$ Randolf Zachow ${ }^{5}$ \\ ${ }^{1}$ Universidade Federal Rural da Amazônia, Campus Capitão Poço, Capitão Poço, Pará, Brasil -anapauladfernandes@yahoo.com.br, \\ ${ }^{2}$ Universidade Federal do Paraná, Departamento de Economia Rural e Extensão, Curitiba, Paraná, Brasil - vitor.ufpr@gmail.com, \\ ajsantos.ufpr@gmail.com, \\ ${ }^{3}$ Embrapa Florestas, Colombo, Paraná, Brasil - evaldo.braz@embrapa.br \\ ${ }^{4}$ Rodrigues de Souza Sociedades Individual de Advocacia, Curitiba, Paraná, Brasil - maraambiental@ hotmail.com \\ ${ }^{5}$ In memoriam
}

Recebido para publicação: 15/03/2017- Aceito para publicação: 30/10/2017

\begin{abstract}
Resumo
O presente trabalho é um estudo de caso sobre o uso sustentável dos recursos florestais por populações tradicionais, envolvendo 137 famílias residentes nos faxinais do município de Mandirituba, estado do Paraná. O objetivo foi analisar a adequação do sistema faxinal no Sistema Nacional de Unidades de Conservação (SNUC) e quantificar os benefícios econômicos associados. Como procedimento de análise de dados, uma matriz descritiva foi desenvolvida a fim de analisar a similaridade das atividades e objetivos das doze categorias do SNUC e do sistema faxinal. A reserva de desenvolvimento sustentável é a categoria de unidade de conservação com características semelhantes às do sistema faxinal, em termos de atividades e objetivos. Os resultados indicaram que a aplicação de instrumentos e programas de política adequados poderiam proporcionar aumento de $350 \%$ na renda e qualidade de vida das populações tradicionais. Além disso, a matriz descritiva se mostrou uma ferramenta importante para adequação de possíveis áreas de conservação no SNUC.

Palavras-chave: Manejo florestal sustentável; conhecimento e cultura tradicional; sistema faxinal; política florestal.
\end{abstract}

\begin{abstract}
Modalities of management of the National System of Conservation Units: a case study in the "Faxinais" of the municipality of Mandirituba, PR. The present work is a case study on the sustainable use of forest resources by traditional populations, which involved 137 faxinal families in the municipality of Mandirituba, Paraná State. The objective was to analyze the adequacy of the faxinal system into the National System of Conservation Units (SNUC) and to quantify the associated economic benefits. In relation to the procedures for data analysis, a descriptive matrix was developed in order to analyze the similitude of the activities and goals of the twelve categories of the SNUC and of the faxinal system. We observed that the Sustainable Development Reserve is the conservation unit category with similitude to the faxinal system in terms of activities and goals. Concluded the adequacy, the implementation of instruments of policy revealed the possibility of an increase of over $350 \%$ on the average family income and on the life quality of traditional populations. Besides, the descriptive matrix has showed as an important tool for adequacy of possible conservation areas in the National System of Conservation Units.

Keywords: Sustainable forest management, traditional knowledge and culture, faxinal community forestry system, forest policy.
\end{abstract}

\section{INTRODUÇÃO}

Comunidades rurais e grupos indígenas em todo o mundo têm participado na proteção de recursos naturais estratégicos, e convenções internacionais vêm procurando traduzir essas práticas em regras universais de proteção a recursos e populações (ALLEGRETTI, 2008). Nesse contexto, devido à demanda global a favor da proteção da natureza, as populações tradicionais passaram a ser consideradas como importantes atores responsáveis pela proteção do ambiente natural no qual estão inseridas (PEREIRA; DIEGUES 2010).

No âmbito da floresta com araucária na região centro-sul do Paraná, encontram-se pequenos povoados tradicionais que desenvolvem atividade silvipastoril em áreas comuns e policultura de subsistência, o sistema

FLORESTA, Curitiba, PR, v. 47, n. 4, p. 459 - 468, out. / dez. 2017.

Donicht,Fernandes, A,P, et al.

ISSN eletrônico 1982-4688

DOI: $10.5380 /$ rf.v47i4.51217 
faxinal, desde a colonização do Estado (LÖWEN SAHR, 2005). A comunidade faxinalense é formada por terrenos justapostos de propriedade de várias famílias que, de forma coletiva, criam seus animais à solta em meio a áreas de florestas (LÖWEN SAHR; CUNHA, 2005). As áreas especiais de uso regulamentado foram criadas com o intuito de proteger porções territoriais do Estado caracterizados pela existência do modo de produção denominado "sistema faxinal", com os objetivos de criar condições para a melhoria da qualidade de vida das comunidades residentes e a manutenção do seu patrimônio cultural, conciliando as atividades agrosilvopastoris com a conservação ambiental e incluindo a proteção de Araucaria angustifolia (pinheiro-do-paraná) (PARANÁ, 1997).

Souza (2007) cita que, apesar do reconhecimento oficial do sistema faxinal pelo Decreto Estadual $\mathrm{n}^{\circ}$ 3.446, de 25 de julho de 1997 (PARANÁ, 1997), a simples presença de um instrumento legal não garante a defesa do "sujeito coletivo que constrói o faxinal", já que não foi levada em consideração a existência dos faxinalenses enquanto categoria étnica, nem suas práticas culturais ou seu formato como grupo social quando formulada a lei que criou as Áreas Especiais de Uso Regulamentado (ARESUR).

Com isso, seus moradores vêm enfrentando diversos conflitos socioambientais que atingem comunidades tradicionais, como a redução do território e dos recursos naturais disponíveis, a ameaça da perda das culturas e tradições e os conflitos com atores externos, representados por vizinhos e setores governamentais (HAUER, 2011). Segundo Grzebieluka e Löwen Sahr (2009), as comunidades faxinalenses vêm perdendo seus laços históricos, sociais e culturais do passado para o avanço tecnológico agrícola. Algumas famílias se integram ao sistema de agricultura industrial, mantendo a terra. Em outras comunidades, ocorre a venda gradativa das terras para chacareiros, que não se integram ao sistema coletivo do faxinal. As desarticulações do sistema faxinal têm implicações econômicas, sociais, ambientais, políticas e culturais para os camponeses que vivem dentro deste tipo de organização, que deixam de ter a relação que antes tinham com a terra, a qual referenciava, também, a sua concepção de mundo (LÖWEN SAHR, 2005).

Nesse contexto, Nerone (2000) sugere, em um dos primeiros trabalhos apresentados com o tema centrado nos faxinais, uma "reeducação do olhar" não somente aos pesquisadores, mas também às demais autoridades, concluindo que há necessidade de um novo enfoque para desvendar a invisibilidade dos faxinais e buscando para eles "saídas econômicas que levem em conta a totalidade do sistema". Diante deste cenário de mudanças na organização faxinal e na luta pelo reconhecimento da manutenção dos seus valores regionais, culturais e sociais, objetivou-se neste estudo analisar o enquadramento do sistema faxinal às 12 categorias de manejo previstas no Sistema Nacional de Unidades de Conservação e quantificar os benefícios econômicos associados.

\section{MATERIAL E MÉTODOS}

\section{Área de estudo}

As comunidades faxinalenses estudadas pertencem ao município de Mandirituba - PR, distantes a 25 $\mathrm{km}$ da sede administrativa do município e a $70 \mathrm{~km}$ da capital do estado do Paraná (Curitiba). O município localiza-se a $25^{\circ} 46^{\prime} 44^{\prime \prime}$ de latitude sul e 49 $19^{\prime} 34^{\prime \prime}$ de longitude oeste, a uma altitude de 925 metros, ocupando uma área de 379,179 km². Em 2010, sua população foi estimada em 22.220 habitantes (IBGE, 2011).

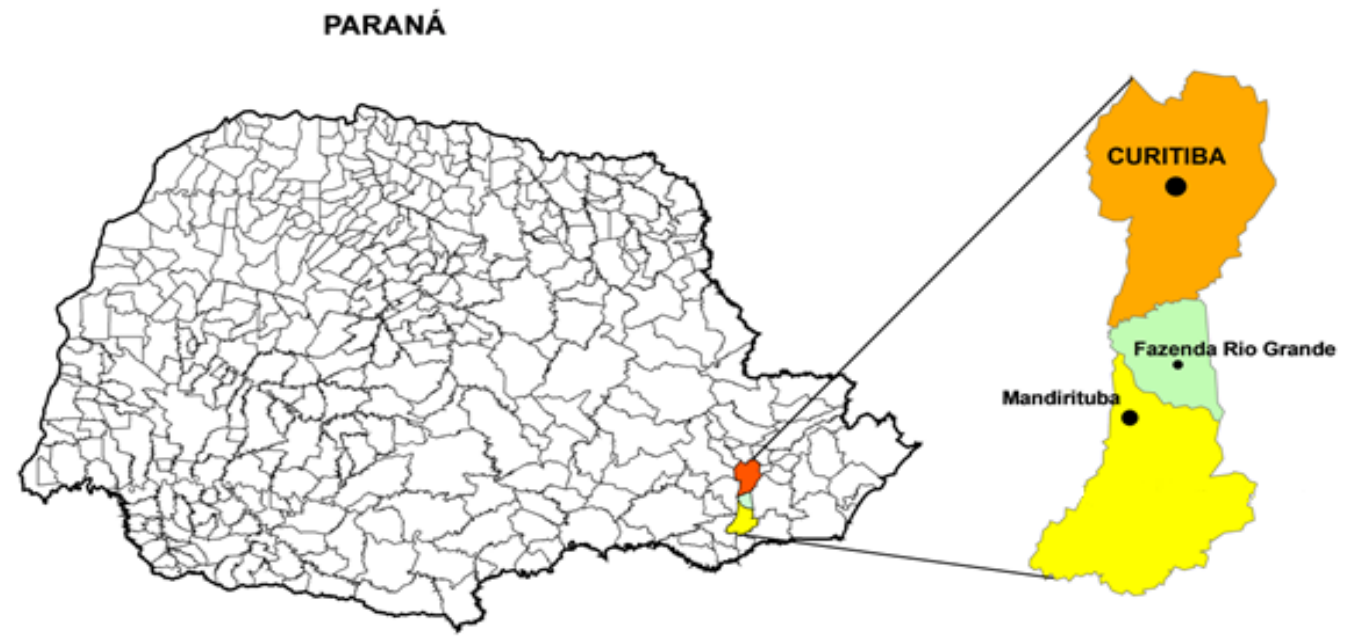

Figura 1. Figura de localização do município de Mandirituba em relação ao estado do Paraná.

Figure 1. Figure of the location of the municipality of Mandirituba in relation to the state of Paraná. FONTE: Departamento de Estudos Socioeconômicos Rurais (DESER, 2012) 


\section{Fonte dos dados}

Esta pesquisa se caracteriza por ser de natureza aplicada com enfoque qualitativo. Com relação aos objetivos, a pesquisa é considerada descritiva e exploratória. Como procedimentos técnicos, a pesquisa de literatura e o estudo de caso foram utilizados.

Foram estudadas três comunidades faxinalenses presentes no município de Mandirituba: Espigão das Antas, Pedra Preta e Meleiro. Para caracterizar o sistema faxinal nos aspectos social, econômico e ambiental, 137 famílias, totalizando 439 pessoas, foram entrevistadas em 2012. As informações-base para a obtenção dos objetivos deste trabalho constam de questionários resultantes do contrato celebrado entre o Instituto Ambiental do Paraná e o DESER, em atendimento ao Edital de Concorrência n. ${ }^{\circ}$ 055/2011-IAP. Os questionários utilizados possuem caráter censitário e semiestruturado, com algumas questões pontuais referentes às variáveis apontadas no art. $2^{\circ}$ do Decreto Estadual n. ${ }^{\circ}$ 3.446/97: densidade populacional, qualidade de vida das populações residentes, organização comunitária, sistemas de produção e nível de comprometimento e empenho dos municípios para com o desenvolvimento social e econômico dos faxinais (PARANÁ, 1997).

\section{Processamento das informações}

Uma matriz descritiva foi elaborada a fim de realizar uma análise comparativa entre os objetivos e atividades produtivas permitidas nas categorias de manejo de unidades de conservação de acordo com a Lei 9985/2000 (BRASIL, 2000), além dos objetivos e atividades desenvolvidas no sistema faxinal. As diferentes variáveis foram codificadas numericamente em relação à permissão (1) ou à restrição (0) de determinada atividade na categoria de manejo da UC analisada. Da mesma forma, foi realizada a codificação em relação aos objetivos de cada categoria de UC, sendo o código " 0 " representativo dos objetivos não praticados por determinada categoria de UC e o código " 1 ” representativo da presença deste objetivo na caracterização da UC. $\mathrm{O}$ código $1 \mathrm{P}$ se refere à atividade não praticada no faxinal atualmente, porém foi identificado potencial em seu desenvolvimento.

A análise comparativa não pretendeu avaliar o grau de importância dos atributos, mas apenas a detecção da presença ou ausência das características relativas a ambas as áreas. Os dados foram armazenados e analisados em planilha eletrônica. Com esse procedimento, foi identificada qual categoria de UC possui a maior similaridade de atributos com relação às características dos sistemas faxinais.

\section{Quantificação dos benefícios econômicos}

Os benefícios econômicos resultantes do enquadramento do sistema faxinal em uma das categorias de manejo previstas no Sistema Nacional de Unidades de Conservação foram identificados e valorados a partir da observação dos instrumentos e mecanismos de política pública aplicados às categorias do SNUC. Essa análise envolveu, especificamente, as atividades desenvolvidas na área de utilização comunitária do sistema faxinal, visto que, nas áreas destinadas ao cultivo de espécies perenes e anuais localizadas no entorno, a situação não difere da dos demais agricultores familiares que não pertencem ao sistema faxinal.

As receitas oriundas das atividades que possuem importante papel na receita monetária dessas famílias foram calculadas utilizando-se informações sobre a quantidade de animais e produtos comercializados e seu preço de venda, extraído do histórico de preços recebidos pelo produtor da Secretaria de Estado da Fazenda (PARANÁ, 2013a). Os benefícios econômicos foram calculados pela diferença entre a receita familiar média anual atual e a receita familiar média anual decorrente da proposta de enquadramento no SNUC. Para determinar a estimativa de receita atual gerada pelas principais atividades desenvolvidas dentro do faxinal, foi considerado o número de 74 famílias que praticam atividades na área comunitária de 156,2 ha.

Para determinar o acréscimo de receita decorrente do enquadramento proposto ao sistema faxinal, foram identificados os instrumentos econômicos e financeiros de políticas públicas que incidem sobre a categoria de UC com maior similaridade com o sistema faxinal, sendo seus benefícios econômicos quantificados. Para o cálculo de isenção de Imposto sobre o Território Rural (ITR), utilizou-se a informação verbal do funcionário da Secretaria de Agricultura de Mandirituba, sendo o valor mínimo pago R\$ 30,00 por hectare no município.

\section{RESULTADOS E DISCUSSÃO}

\section{Matriz de relação entre os requisitos previstos no SNUC e no sistema faxinal}

A partir dos objetivos/definições das modalidades de gestão do SNUC identificados e com base nos resultados da avaliação da situação das comunidades faxinalenses, uma matriz de relação é apresentada (Quadro 1). A matriz lista as atividades e os objetivos que compõem as 12 (doze) unidades de conservação estabelecidas no SNUC e as definições para o sistema faxinal. A Tabela 1 mostra a restrição na realização de atividades

FLORESTA, Curitiba, PR, v. 47, n. 4, p. 459 - 468, out. / dez. 2017.

Donicht,Fernandes, A,P, et al.

ISSN eletrônico 1982-4688

DOI: $10.5380 /$ rf.v47i4.51217 
produtivas nas modalidades do grupo das unidades de proteção integral, representados pelo código "0", que identifica a ausência ou a não autorização de determinada atividade de uso direto nos limites da unidade de conservação. Esse fato não foi identificado nas modalidades do grupo das unidades de uso sustentável, uma vez que o objetivo básico desse grupo é compatibilizar a conservação da natureza com o uso sustentável de parcela dos seus recursos naturais.

Pela interpretação dos códigos estabelecidos na matriz, é possível observar que as categorias de UC Reserva Biológica (RB) e Estação Ecológica (EE) não possuem diferenciação em termos de atividades e objetivos, sendo as mais restritivas em termos de atividades de uso e visitação. Pela semelhança entre os objetivos de manejo das categorias Reserva Biológica e Estação Ecológica, foi sugerida a exclusão da categoria Reserva Biológica do SNUC. Entretanto, por reconhecimento à enorme contribuição dada pelo Prof. Paulo Nogueira no que se refere à proteção dos recursos naturais do país, a proposta não foi aprovada, mantendo-se ambas as categorias no Sistema. Atualmente, isso é motivo de críticas, pois a sobreposição continua a existir, o que causa muita confusão (SOUZA, 2012).

Quadro 1. Matriz de relação entre os requisitos das modalidades do SNUC e o sistema faxinal. Table 1. Matrix of relationship among the requirements of the SNUC and the faxinal system.

\begin{tabular}{|c|c|c|c|c|c|c|c|c|c|c|c|c|c|c|}
\hline & \multirow[b]{4}{*}{ Características específicas } & \multirow{2}{*}{\multicolumn{12}{|c|}{ Modalidades de unidades de conservação }} & \multirow[b]{4}{*}{ S. faxinal } \\
\hline & & & & & & & & & & & & & & \\
\hline & & \multicolumn{5}{|c|}{ Proteção integral } & \multicolumn{7}{|c|}{ Uso sustentável } & \\
\hline & & $\mathrm{RB}$ & & $\mathrm{PN} / \mathrm{N}$ & $\mathrm{MN} R$ & $\mathrm{RVS}$ & APA & ARIE & $\mathrm{FN}$ & RE & $\mathrm{RF}$ & RDS & RPPN & \\
\hline \multirow{11}{*}{$\frac{\pi}{2}$} & Moradia de comunidades tradicionais & 0 & 0 & 0 & 0 & 0 & 1 & 0 & 1 & 1 & 0 & 1 & 0 & 1 \\
\hline & Produção animal & 0 & 0 & 0 & 0 & 0 & 1 & 1 & 1 & 1 & 0 & 1 & 0 & 1 \\
\hline & Produção de recursos madeireiros & 0 & 0 & 0 & 0 & 0 & 1 & 1 & 1 & 1 & 0 & 1 & 0 & 1 \\
\hline & Produção de produtos extrativistas & 0 & 0 & 0 & 0 & 0 & 1 & 1 & 1 & 1 & 0 & 1 & 0 & 1 \\
\hline & Produção agrícola & 0 & 0 & 0 & 0 & 0 & 1 & 1 & 1 & 1 & 0 & 1 & 0 & 1 \\
\hline & Manejo/uso múltiplo dos recursos naturais & 0 & 0 & 0 & 0 & 0 & 1 & 1 & 1 & 1 & 1 & 1 & 1 & 1 \\
\hline & Manejo indireto dos recursos naturais & 0 & 0 & 1 & 1 & 1 & 1 & 1 & 1 & 1 & 1 & 1 & 1 & 1 \\
\hline & Pesquisa científica & 1 & 1 & 1 & 1 & 1 & 1 & 1 & 1 & 1 & 1 & 1 & 1 & 1 \\
\hline & Atividades de recreação e serviços de turismo & 0 & 0 & 1 & 1 & 1 & 1 & 1 & 1 & 1 & 1 & 1 & 1 & $1 \mathrm{P}$ \\
\hline & Atividades de educação ambiental & 1 & 1 & 1 & 1 & 1 & 1 & 1 & 1 & 1 & 1 & 1 & 1 & $1 \mathrm{P}$ \\
\hline & Manejo de recursos da fauna/flora & 1 & 1 & 1 & 1 & 1 & 1 & 1 & 1 & 1 & 1 & 1 & 1 & 1 \\
\hline \multirow{7}{*}{$\begin{array}{l}0 \\
0 \\
0 \\
0 \\
0\end{array}$} & Proteção de sítios culturais e arqueológicos & 0 & 0 & 1 & 1 & 0 & 1 & 0 & 0 & 0 & 0 & 1 & 1 & 1 \\
\hline & Preservação/restauração de ecossistemas & 1 & 1 & 1 & 1 & 1 & 1 & 1 & 1 & 1 & 1 & 1 & 1 & 1 \\
\hline & Proteção de espécies raras/endêmicas/vulneráveis & 1 & 1 & 1 & 0 & 1 & 1 & 1 & 1 & 1 & 1 & 1 & 1 & 1 \\
\hline & Uso sustentável dos recursos naturais & 0 & 0 & 0 & 0 & 0 & 1 & 1 & 1 & 1 & 1 & 1 & 0 & 1 \\
\hline & Proteção de paisagens/belezas cênicas & 0 & 0 & 1 & 1 & 1 & 1 & 1 & 0 & 0 & 0 & 0 & 1 & 1 \\
\hline & Proteção de sítios abióticos & 1 & 1 & 1 & 1 & 1 & 1 & 1 & 0 & 0 & 0 & 1 & 1 & 1 \\
\hline & Conservação de bacias hidrográficas & 1 & 1 & 1 & 1 & 1 & 1 & 1 & 1 & 1 & 1 & 1 & 1 & 1 \\
\hline
\end{tabular}

Por outro lado, a Área de Proteção Ambiental (APA) é considerada a mais flexível quanto ao uso dos recursos naturais, visitação e ocupação. Pode-se inferir, ainda, que a Reserva de Fauna e a Reserva Particular do Patrimônio Natural, apesar de estarem enquadradas no grupo das unidades de conservação de uso sustentável, não permitem nenhum tipo de atividade agrícola, pecuária ou extrativista nos seus limites. Percebe-se que a presença da RPPN e da RF entre o grupo das unidades de uso sustentável está deslocada. Estas deveriam integrar o grupo das unidades de proteção integral, uma vez que somente é permitido o uso indireto de seus atributos. Pelo projeto original, a RPPN era apenas um mecanismo de incentivo à conservação em terra privada e não integrava o SNUC. Reconhecendo seu papel fundamental na conservação da natureza, o Deputado Fernando 
Gabeira atribuiu a essas áreas o status de componente do SNUC do grupo das UCs de Proteção Integral (MERCADANTE, 2011). Segundo Souza (2012), a categoria Reserva de Fauna na atual configuração jurídica não deveria existir, uma vez que os estudos técnicos e científicos sobre o manejo econômico sustentável de recursos faunísticos podem ser realizados na categoria Estação Ecológica ou qualquer outra UC.

Observa-se, ainda, que quatro modalidades de unidade de conservação de ambos os grupos permitem a posse e o uso das áreas ocupadas pelas populações tradicionais (Área de Proteção Ambiental - APA, Floresta Nacional - FLONA, Reserva de Desenvolvimento Sustentável - RDS e Reserva Extrativista - RESEX). A partir da interpretação dos resultados apresentados na matriz de relação, verificou-se que as categorias de unidade de conservação APA, FLONA, RDS e RESEX são as que mais se assemelham ao sistema faxinal conforme as variáveis analisadas.

A tabela 1 apresenta uma análise comparativa entre essas categorias do SNUC em termos de participação da comunidade na gestão e questões fundiárias para determinar o melhor enquadramento do sistema faxinal.

Tabela 1. Características de gestão e uso da terra das modalidades de UC.

Table 1. Features of management and land use of the Protected Areas categories.

\begin{tabular}{lllll}
\hline & Gestão & Situação fundiária & Uso da terra & Tipo de uso \\
\hline APA & Não definida pelo SNUC & Pública ou privada & Normas e restrições & Individual \\
\hline RESEX & Conselho deliberativo & Domínio público & Plano de manejo & Coletivo \\
\hline RDS & Conselho deliberativo & Domínio público & Plano de manejo & Coletivo \\
\hline FLONA & Conselho consultivo & Posse e domínio público & Plano de manejo & Individual \\
\hline
\end{tabular}

Fonte: Brasil (2000), adaptado pelos autores.

A Lei do SNUC não deixa claro o tipo de conselho para as APAs, no entanto a maioria das APAs vem tratando seus conselhos como consultivos. Pela análise das questões levantadas na Tabela 2, é possível verificar que a melhor forma de participação dos faxinalenses nas decisões e gestão das áreas das comunidades seria a deliberativa, uma vez que a atuação dos conselhos deliberativos é pautada pela participação direta das comunidades nas decisões tomadas.

Com relação ao sistema comunitário das famílias que possuem a posse da terra que está sob domínio público, nota-se que essa situação fundiária não implica no desenvolvimento de suas ações, pois o uso da terra é estabelecido por meio de plano de manejo para essas áreas conforme o modelo de unidade de conservação a ser seguido. Apesar de as terras de ambas as categorias de unidade de conservação (RDS e RESEX) serem de domínio público, a desapropriação é obrigatória na RESEX. Já na RDS, podem coexistir terras de domínio público e áreas particulares incluídas em seu limite. Dos Santos (2010) cita que apenas a categoria RDS tem natureza dominial híbrida. Ao mesmo tempo em que seu domínio é público e seu uso é concedido às populações tradicionais, podem coexistir áreas particulares incluídas em seus limites.

As atividades que serão desenvolvidas pelos faxinalenses são validadas mediante um contrato de concessão de direito real de uso. O uso da terra deve estar fundamentado no plano de manejo, o qual deve fornecer as diretrizes para o uso da área e o manejo dos recursos naturais, sendo o uso de forma coletiva para toda comunidade.

O Quadro 1 e a Tabela 1 mostram que a RDS agrega características e valores que ressaltam suas semelhanças com o sistema faxinal, sendo a categoria mais adequada para a inclusão do sistema faxinal. Observando todos os resultados obtidos neste estudo, notou-se que o enquadramento feito a partir do disposto no art. $1^{\circ} \S 2^{\circ}$ do Decreto n. ${ }^{\circ} 3.446 / 97$ (PARANÁ, 1997), o qual discorre que a ARESUR observará as disposições legais aplicáveis às APAs na perspectiva do desenvolvimento do sistema faxinal, no que couber, não foi definido com base em estudos das características e objetivos relevantes às comunidades faxinalenses, uma vez que foi demonstrado que a RDS agrega características e valores que ressaltam suas semelhanças com o sistema faxinal, e não as APAs.

Recentemente, o Paraná incluiu quatro novas áreas nos termos das Áreas Especiais de Uso Regulamentado: Faxinal Sete Saltos de Baixo, em Ponta Grossa; Faxinal de São Roquinho e Faxinal Bom Retiro, localizados no município de Pinhão; e Faxinal Saudade Santa Anita, no município de Turvo. Porém, as comunidades faxinalenses Campestre dos Paula, Meleiro, Espigão das Antas e Pedra Preta, que já haviam conseguido o reconhecimento como Áreas Especiais de Uso Regulamentado, tiveram seu registro cancelado pela Secretaria Estadual do Meio Ambiente. Conforme o documento publicado em Diário Oficial no dia 02 de maio de 2011, o cancelamento se justificou pelo "conflito de competência entre as autarquias desta Secretaria e manifestação contrária das comunidades faxinalenses” (ALMEIDA, 2008).

FLORESTA, Curitiba, PR, v. 47, n. 4, p. 459 - 468, out. / dez. 2017.

Donicht,Fernandes, A,P, et al.

ISSN eletrônico 1982-4688

DOI: $10.5380 /$ rf.v47i4.51217 
É observada uma insegurança jurídica na criação dessas áreas e na manutenção das populações nas suas terras, uma vez que a inclusão de comunidades faxinalenses na categoria de ARESUR é baseada em um decreto

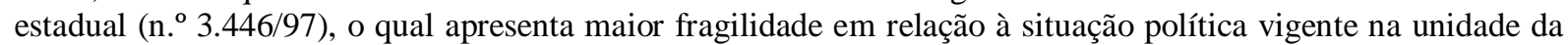
federação. Dessa forma, o enquadramento do sistema faxinal em uma das doze categorias do SNUC ao invés de sua inclusão em uma categoria que não é contemplada diretamente pela lei traria maior estabilidade política e legal às populações tradicionais, uma vez que a lei federal é menos propensa a mudanças do que as leis estaduais e municipais, além da maior possibilidade de utilização dos instrumentos legais de desenvolvimento.

\section{Quantificação dos benefícios econômicos atuais}

O valor unitário de venda da produção do sistema faxinal em janeiro de 2012 e a receita média por família são apresentados na tabela 2 .

Tabela 2. Produção e receitas geradas pelas principais atividades por ano.

Table 2. Production and revenues generated by main activities per year.

\begin{tabular}{lllll}
\hline ATIVIDADE & Produção* & Valor unitário $(\mathbf{R} \$)$ & Receita total $(\mathbf{R} \mathbf{)}$ & Receita por família (R\$/ano) \\
\hline Aves & $873 \mathrm{cab}$ & 2,91 & $2.540,43$ & 34,33 \\
\hline Bovinos & $38 \mathrm{cab}$ & 93,38 & $3.548,44$ & 47,95 \\
\hline Caprinos & $20 \mathrm{cab}$ & 50,00 & 1000,00 & 13,51 \\
\hline Suínos & $585 \mathrm{cab}$ & 28,95 & $16.935,75$ & 228,86 \\
\hline Ovos & $1.294 \mathrm{dz}$ & 1,52 & $1.966,88$ & 26,58 \\
\hline Pinhão & $1.050 \mathrm{~kg}$ & 6,0 & $6.300,00$ & 85,14 \\
\hline Erva-mate & $1.000 \mathrm{~kg}$ & 6,90 & $6.900,00$ & 93,24 \\
\hline TOTAL & & & $\mathbf{3 9 . 1 9 1 , 5 0}$ & $\mathbf{5 2 9 , 6 1}$ \\
\hline
\end{tabular}

*Em que: cab = cabeça; $\mathrm{dz}=$ dúzias; $\mathrm{kg}$ = quilograma.

A tabela 2 apresenta a receita anual por família, resultante da comercialização dos produtos das principais atividades praticadas dentro da área dos faxinais, sendo utilizado o valor do frango vivo com $1,5 \mathrm{~kg}$ para as aves e a massa para abate de $15 \mathrm{~kg}$ para os suínos, conforme referência dos faxinalenses. Dessa forma, a receita média anual por família gerada pelo sistema atual foi de R 529,61 (US\$ 295.70¹).

\section{Benefícios resultantes da reclassificação do sistema faxinal e da implementação de instrumentos e programas de política agrícola}

Como instrumento econômico de incentivo direto e indireto à conservação ambiental, o ICMS ecológico se insere como uma das ferramentas que auxiliam os municípios a cuidar dos mananciais de abastecimento e das áreas do entorno das unidades de conservação. Do total do ICMS arrecadado pelo estado do Paraná, 5\% é destinado para os municípios, proporcionalmente às unidades de conservação em função do tamanho, importância, grau de investimento na área, manancial de captação e outros fatores. Esses 5\% são destinados aos municípios da seguinte forma:

- $\quad 50 \%$ para municípios que tenham, em seu território, mananciais de abastecimento cuja água se destina ao abastecimento da população de outro município;

- $50 \%$ para municípios que tenham integrado, em seu território, unidades de conservação, áreas de terras indígenas, reservas particulares do patrimônio natural, faxinais, reservas florestais legais.

O valor do repasse do Estado correspondente ao ICMS ecológico, para o município de Mandirituba, foi de aproximadamente R\$ 153 mil no ano de 2012 (PARANÁ, 2013b). No entanto, como o município não está inserido na tabela de recursos do ICMS ecológico gerados por unidade de conservação, conclui-se que este repasse se refere apenas às áreas de interesse de mananciais de abastecimento público.

A partir do exposto, fica evidenciada a importância do sistema faxinal ser reconhecido como unidade de conservação pertencente ao SNUC, como forma de obter a garantia de recebimento de $50 \%$ do repasse do ICMS ecológico para municípios com unidades de conservação ambiental. Se as comunidades faxinalenses fossem enquadradas como unidades de conservação no Instituto Ambiental do Paraná, o município receberia a outra metade (R\$ 153 mil) dos 5\% do ICMS arrecadado pelo Estado, correspondente aos municípios que tenham integrado em seu território as áreas discriminadas anteriormente. Para os faxinalenses, o ICMS ecológico contribuiria como acréscimo de receita às famílias, uma vez que deixariam de gastar recursos próprios com

${ }^{1}$ Tomando como base a cotação média do dólar americano no mês de fevereiro de 2012 de R\$ 1,791. 
melhorias de infraestrutura e passariam a receber materiais e recursos da prefeitura. Como o ICMS ecológico é compartilhado entre as famílias da unidade de conservação, o valor de R\$ 153 mil seria dividido pelas 137 famílias das três comunidades do município. Nesse caso, o valor a ser investido na comunidade do estudo por cada família seria de $\mathrm{R} \$ 1.116,78$ ao ano.

Outra forma de incentivo fiscal, já utilizado no cenário nacional e aplicável ao sistema faxinal enquadrado na categoria de RDS, é a isenção do pagamento do Imposto Territorial Rural (ITR). Considerando o valor base de $\mathrm{R} \$ 30,00$ por hectare como sendo o valor mínimo pago de ITR no município, os faxinalenses deixariam de pagar, no mínimo, $\mathrm{R} \$ 4.686,00$ por ano, quantia que seria mantida como receita para as famílias.

O enquadramento do sistema faxinal como unidade de conservação de uso sustentável na categoria de RDS poderia beneficiar as famílias dos faxinalenses, enquadrando-as no Programa Bolsa Verde, Decreto . $^{\circ}$ 7.572 de 28 de setembro de 2011 (BRASIL, 2011), o qual destina esse auxílio para:

- famílias que possuem receita familiar per capita menor que R\$70,00;

- famílias que são beneficiárias do Programa Bolsa Família;

- famílias que desenvolvem atividades de uso sustentável dos recursos naturais em unidades de conservação de uso sustentável, assentamentos ambientalmente diferenciados da reforma agrária, territórios ocupados por comunidades tradicionais, quilombolas, ribeirinhos, extrativistas ou outras áreas rurais definidas por ato do Poder Executivo (BRASIL, 2011).

O valor pago pelo Programa Bolsa Verde às famílias que desenvolvem atividades de conservação ambiental corresponde a $\mathrm{R} \$ 300,00$ por trimestre por família, sem previsão legal de reajuste (valor de referência: janeiro de 2012).

$\mathrm{Na}$ tabela 3, são apresentados os instrumentos e programas de política que poderiam beneficiar o sistema faxinal enquadrado na modalidade de gestão RDS. O quadro permite mostrar o acréscimo de receita familiar média por ano.

Tabela 3. Quantificação dos benefícios econômicos resultantes.

Table 3. Measurement of the resulting economic benefits.

\begin{tabular}{ll}
\hline Instrumentos e programas de política & Receita por família (R\$/ano) \\
\hline ICMS Ecológico & $1.116,78$ \\
\hline Isenção de ITR & 63,32 \\
\hline Bolsa Verde & $1.200,00$ \\
\hline TOTAL & $\mathbf{2 . 3 8 0 , 1 0}$ \\
\hline Fonte: Os autores. &
\end{tabular}

Com base nos valores da tabela 3, resultantes da reclassificação do sistema faxinal, percebe-se que o enquadramento como RDS pode gerar um acréscimo na receita familiar média anual de R\$1.850,49 (US\$ 1033.21), calculado pela diferença entre a receita familiar média anual atual (R\$ 529,61 ou US\$295.71) e a receita familiar média anual decorrente da reclassificação (R\$ 2.380,10 ou US\$ 1328.92). Esse aumento representaria um incremento na receita familiar média anual de aproximadamente $350 \%$.

\section{CONCLUSÕES}

- O atual enquadramento do sistema faxinal na categoria de ARESUR não proporciona benefícios associados às políticas públicas estabelecidas para as diferentes categorias componentes do SNUC;

- Na forma de gestão do faxinal como ARESUR, não foram identificadas ações de apoio reais à conservação dos recursos florestais e à manutenção das comunidades;

- Para o estudo de caso em questão, a matriz descritiva indicou que a Reserva de Desenvolvimento Sustentável (RDS) agrega o maior número de características e valores que ressaltam suas semelhanças com o sistema faxinal. Os benefícios econômicos decorrentes do enquadramento do sistema faxinal nos termos da Reserva de Desenvolvimento Sustentável (RDS) podem possibilitar um incremento na receita familiar média anual de aproximadamente $350 \%$ sobre a receita atual.

\section{REFERÊNCIAS}

ALLEGRETTI, M. A construção social de políticas públicas. Chico Mendes e o movimento dos seringueiros. Desenvolvimento e Meio Ambiente, Curitiba, n. 18, p. 39-59, 2008.

FLOREST A, Curitiba, PR, v. 47, n. 4, p. 459 - 468, out. / dez. 2017.

Donicht,Fernandes, A,P, et al.

ISSN eletrônico 1982-4688

DOI: $10.5380 /$ rf.v47i4.51217 
ALMEIDA, A. W. B. de (Org.). Faxinalenses no Setor Sul - Paraná. Nova cartografia social dos povos e comunidades tradicionais do Brasil. Manaus: Projeto Nova Cartografia Social da Amazônia; UEA Edições, 2008 (Série: Faxinalenses do Núcleo Metropolitano do Sul de Curitiba - Paraná).

BRASIL. Lei $n^{0}$ 9.985, de 18 de julho de 2000. Regulamenta o art. 225, $\S 1^{\text {o }}$, incisos I, II, III e VII da Constituição Federal, institui o Sistema Nacional de Unidades de Conservação da Natureza e dá outras providências. Diário Oficial da União, Brasília, 18 de julho de 2000.

BRASIL, Lei $n^{0}$ 12.512, de 14 de outubro de 2011. Institui o Programa de Apoio à Conservação Ambiental e o Programa de Fomento às Atividades Produtivas Rurais; altera as Leis n ${ }^{\circ} 10.696$, de 2 de julho de 2003, 10.836, de 9 de janeiro de 2004, e 11.326, de 24 de julho de 2006. Diário Oficial da União, Brasília, 14 de outubro de 2011.

DESER. Produto 3 - diagnóstico do Faxinal Espigão das Antas - Mandirituba-PR, proposta técnica em atendimento ao Edital de Concorrência n ${ }^{\circ}$ 055/2011-IA. Departamento de Estudos Socioeconômicos rurais. Curitiba, 2012.

DOS SANTOS, V. B. A coexistência da propriedade privada na reserva de desenvolvimento sustentável. Fundação Amazonas Sustentável (FAS), 2010. Disponível em: 〈www.fas-amazonas.org>. Acesso em: 23/08/2014.

GRZEBIELUKA, D.; LÖWEN SAHR, C. L. Comunidades de faxinal e suas dinâmicas sócio espaciais: da formação à desagregação de uma tradição no município de Tibagi (PR) - um estudo sobre o faxinal dos empoçados. Revista Geografar, Curitiba, v. 4, n. 1, p. 34-58, 2009.

HAUER, M. Singularidades do sistema faxinalense. In: I SIMPÓSIO DE PESQUISADORES DE FAXINAIS: ESTADO DA ARTE E PERSPECTIVAS, 2011. Ponta Grossa: PPG Gestão do Território/UEPG, 2011.

IBGE. Censo Demográfico 2010. Características da população e dos domicílios: resultados do universo. Rio de Janeiro: IBGE, 2011.

LÖWEN SAHR, C. L. Preservação e revitalização do sistema faxinal na região da mata de araucária do Paraná: um projeto extensionista. Revista Conexão, Ponta Grossa, v. 1, n. 1, p. 42-46, 2005.

LÖWEN SAHR, C. L.; CUNHA, L. A. G. O significado social e ecológico dos faxinais: reflexões acerca de uma política agrária sustentável para a região da mata com araucária no Paraná. Revista Emancipação, Ponta Grossa, n. 5. p. 89-104, 2005.

MERCADANTE, M. Uma década de debate e negociação: a história da elaboração da lei do SNUC. In: HERMAN, B. A. (Org.) Direito ambiental das áreas protegidas: o regime jurídico das unidades de conservação. Forense Universitária, 2001. p. 190-231.

NERONE, M. M. Terras de plantar, terras de criar - sistema faxinal: Rebouças - 1950-1997. 286 f. (Doutorado em História) - Programa de Pós-Graduação da Faculdade de Ciências e Letras da Universidade Estadual Paulista, Campus de Assis, São Paulo, 2000.

PARANÁ. Decreto Estadual n ${ }^{0} 3.446$, de 14 de agosto de 1997. Dispõe sobre as ARESUR - Áreas Especiais de Uso Regulamentado, que abrangem porções territoriais do Estado caracterizadas pela existência do modo de produção denominado Sistema Faxinal. Diário Oficial do Paraná, Curitiba.

PARANÁ. Secretaria da Agricultura e do Abastecimento. Preço médio recebidos pelo produtor. Disponível em: <http://www.agricultura.pr.gov.br/modules/conteudo/conteudo.php?conteudo=195>. Acesso em: 22 nov. 2013.

PARANÁ. Secretaria de Estado da Fazenda. Tabela de municípios com participação no índice ambiental valores repassados no exercício de 2012. Disponível em: <http://www.icmsecologico.org.br/tabelas/pr\%20 tabela\%202012.pdf>. Acesso em: 26 nov. 2013.

PEREIRA, B. E.; DIEGUES, A. C. Conhecimento de populações tradicionais como possibilidade de conservação da natureza: uma reflexão sobre a perspectiva da etnoconservação. Revista Desenvolvimento e Meio Ambiente, n. 22, p. 37-50, 2010.

SOUZA, R. M. Da invisibilidade para a existência coletiva: redefinindo fronteiras étnicas e territoriais mediados pela construção da identidade coletiva de povos faxinalenses. In: SEMINÁRIO NACIONAL MOVIMENTOS SOCIAIS, PARTICIPAÇÃO E DEMOCRACIA, 2007, Universidade Federal de Santa Catarina, Florianópolis, Brasil, 2007. 
SOUZA, M. F. R. de. Políticas públicas relacionadas às unidades de conservação do Brasil: uma análise crítica. 271 f. Tese (Doutorado em Política e Economia Florestal) - Setor de Ciências Agrárias, Universidade Federal do Paraná, Curitiba, 2012.

FLOREST A, Curitiba, PR, v. 47, n. 4, p. 459 - 468, out. / dez. 2017.

Donicht,Fernandes, A,P, et al.

ISSN eletrônico 1982-4688

DOI: $10.5380 /$ rf.v47i4.51217 
FLORESTA, Curitiba, PR, v. 47, n. 4, p. 459 - 468, out/dez. 2017. 